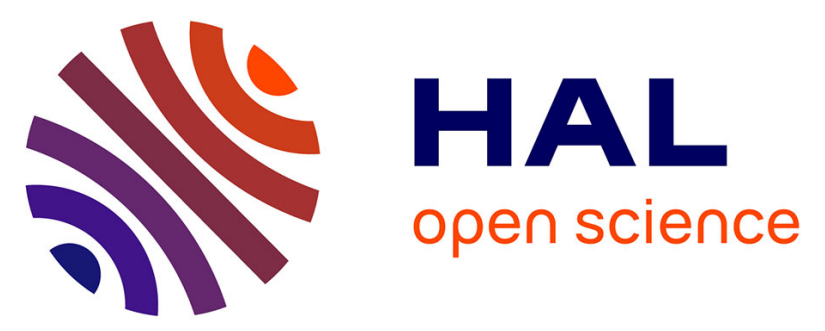

\title{
A Multiobjective Optimization Framework for the Embodiment Design of Mechatronic Products Based on Morphological and Design Structure Matrices
}

Didier Casner, Rémy Houssin, Jean Renaud, Dominique Knittel

\section{- To cite this version:}

Didier Casner, Rémy Houssin, Jean Renaud, Dominique Knittel. A Multiobjective Optimization Framework for the Embodiment Design of Mechatronic Products Based on Morphological and Design Structure Matrices. 12th IFIP International Conference on Product Lifecycle Management (PLM), Oct 2015, Doha, Qatar. pp.813-825, 10.1007/978-3-319-33111-9_74 . hal-01377511

HAL Id: hal-01377511

https://hal.inria.fr/hal-01377511

Submitted on 7 Oct 2016

HAL is a multi-disciplinary open access archive for the deposit and dissemination of scientific research documents, whether they are published or not. The documents may come from teaching and research institutions in France or abroad, or from public or private research centers.
L'archive ouverte pluridisciplinaire HAL, est destinée au dépôt et à la diffusion de documents scientifiques de niveau recherche, publiés ou non, émanant des établissements d'enseignement et de recherche français ou étrangers, des laboratoires publics ou privés.

\section{(ㄷ)(i)}

Distributed under a Creative Commons Attribution| 4.0 International License 


\title{
A multiobjective optimization framework for the embodiment design of mechatronic products based on morphological and design structure matrices
}

\author{
Didier Casner ${ }^{1,}$, Rémy Houssin ${ }^{1,2}$, Jean Renaud ${ }^{1}$, Dominique Knittel ${ }^{1,2}$ \\ ${ }^{1}$ INSA of Strasbourg, LGECO, 24 bd de la Victoire, 67084 Strasbourg Cedex, France \\ didier.casner@insa-strasbourg.fr ; jean.Renaud@insa-strasbourg.fr \\ ${ }^{2}$ University of Strasbourg, , 3-5 rue de l'Université, 67000 Strasbourg, France \\ rémy.houssin@unistra.fr ; dominique.knittel@unistra.fr
}

\begin{abstract}
This paper deals with the embodiment design of mechatronic product and is intended for proposing a novel design support framework based on multiobjective optimization approaches. This framework builds design architectures by aggregating solution principles presented within a morphological matrix. Then, the solution principles are analyzed against compatibility. This compatibility analysis results in a design structure matrix. Once this compatibility analysis has been performed, the optimization framework developed in this paper is applied to find combination of solution principles. We showed the application of our framework for the embodiment design of a wind turbine.
\end{abstract}

Keywords: Design process, Mechatronic product, multiobjective optimization, Design Structure Matrix, Embodiment design.

\section{Problematic}

A product is designed [1] to satisfy a need expressed by a client or provide a service to him. A wide number of contributions were carried in the field of design engineering to propose different design processes and methods. They all describe them as a phase-type process of different granularity with phases such as [1]: clarification of the task [2,3], conceptual design [4-6], embodiment design [7, 8], and detail design $[9,10]$. Our research works are therefore intended to propose new design methods and tools, based on multiobjective optimization approaches, to develop more efficient, more innovative mechatronic systems [11, 12] integrating more features, requiring less time to design them and being cheaper. This paper focuses on the support of the embodiment design of mechatronic systems, not only in terms of architecture generation but also in architecture selection. To use optimization tools, it is required to express the design problem as an optimization problem, including several criteria and constraints, in a mathematical form.

This paper is divided in four parts. The first part presents a literature review on methods used within the embodiment design phase to generate and select 
architectures. The second part details our framework and its implementation. The third part shows the application of the presented framework to the embodiment design of a wind turbine. The fourth and final part exposes a conclusion and introduces research directions for the future research.

A specialized company asked us to solve a problem related to the design of wind turbines. This company wants to improve the performance of their wind turbines regarding its design strategy. In this strategy, engineers are independently designing and optimizing the different components of the wind turbine. Whilst the components are themselves optimal, it does not produce an optimal global wind turbine, as the problem is nonlinear and non-convex. With the company, we defined the objectives of our design problem and the functional architecture of the turbine [12] shown in figure 1. This approach includes three phases: the first phase deals with the definition of the functional architecture, the second one aims developing subsystems from the mechatronic system, and the third one integrates the subsystems within the global mechatronic system and optimizes this integration.

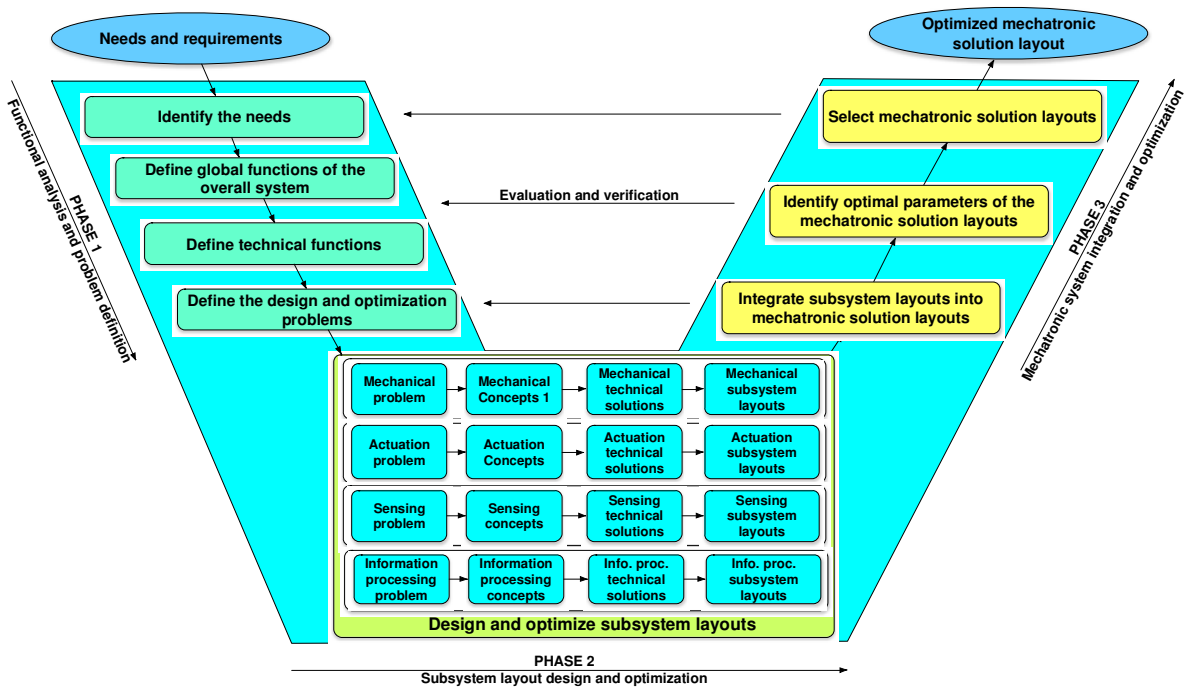

Fig. 1. Developed design method, presented in [12]

The preliminary study realized by the company shows that, in the installation site, the wind distribution at 50 meters follows a Weibull distribution with shape parameter equal to 2.39 and scale parameter equal to $12.02 \mathrm{~m} / \mathrm{s}$. After this study, we defined with the company the functional architecture of the turbine that leads to the definition of the following technical functions shown in table 1. Then we defined the morphological matrix the solution principles that can be applied to realize each technical function. They then entrusted us to find the optimal layouts by selecting and combining the solution principles defined in the matrix in order to: 1) Maximize the energy produced and supplied to the cottage. 2) Minimize the cost of energy. 3) Maximize the reliability of the wind turbine. 
Table 1. Solution principles for the wind turbine

\begin{tabular}{|c|c|c|c|}
\hline Technical functions & & Solution principles & \\
\hline Capture wind energy & Rotor with blades & & \\
\hline Maintain in high altitude & Tower & $\begin{array}{l}\text { Structure filled with } \\
\text { helium gas }\end{array}$ & \\
\hline Adjust altitude & Cable & None & \\
\hline Adjust power & Gearbox & $\begin{array}{l}\text { Multi-ratio gear } \\
\text { transmission }\end{array}$ & \\
\hline Produce electricity & $\begin{array}{l}\text { Single phase } \\
\text { synchronous } \\
\text { machine }\end{array}$ & $\begin{array}{c}\text { Three phase } \\
\text { synchronous } \\
\text { machine }\end{array}$ & $\begin{array}{c}\text { Three phase } \\
\text { asynchronous } \\
\text { machine }\end{array}$ \\
\hline Adjust velocity & $\begin{array}{l}\text { Hypersynchronous } \\
\text { cascade }\end{array}$ & $\begin{array}{l}\text { Hyposynchronous } \\
\text { cascade }\end{array}$ & \\
\hline Store produced electricity & Battery & Supercapacitor & \\
\hline $\begin{array}{l}\text { Convert AC to DC power } \\
\text { Adjust DC voltage }\end{array}$ & $\begin{array}{c}\text { Single phase rectifier } \\
\text { Chopper }\end{array}$ & $\begin{array}{c}\text { Three phase rectifier } \\
\text { None }\end{array}$ & None \\
\hline $\begin{array}{l}\text { Convert DC to AC power } \\
\text { Supervise the system }\end{array}$ & $\begin{array}{c}\text { Single phase inverter } \\
\text { Processor }\end{array}$ & $\begin{array}{l}\text { Three phase inverter } \\
\text { Embedded system }\end{array}$ & None \\
\hline
\end{tabular}

\section{Literature review}

The literature review focuses on matrix approaches and tools that have been developed to support the design process. Matrix methods are mainly used when the architectures are modifications of already existing products, which is the case for most designs [13]. The authors think that inventive design approaches are mainly used to solve problems when existing architectures are not enough efficient. The matrices are typically used to map and visualize relations between properties of the product and/or activities in the design process. One example of such a matrix method is the House of Quality from Quality Function Deployment (QFD) [14, 15] where customer requirements are mapped to engineering characteristics [16]. Suh [17] developed a system design methodology based on a matrix approach to systematically analyze the transformation of customer needs into functional requirements, design parameters and process variables. The design matrix from axiomatic design maps the relationship between the functional requirements and the design parameters. Axiomatic design is based on two axioms, the independence and information axioms, which are based on the properties of matrix and should lead to a "good" design [18].

The design structure matrix (DSM) provides a simple, compact, and visual representation of a complex system that supports innovative solutions to decomposition and integration problems. This DSM can be useful to identify compatibilities, incompatibilities and dependencies between the different solution principles[19]. In 1948, Fritz Zwicky [20, 21] introduced morphology as a method of thinking whose idea is to systematically search for a solution to a problem by trying out all possible combinations in a matrix. Also named morphological box or chart in the literature, the morphological matrix is created by decomposing the main function of the product into subfunctions, using methods such as the Functional Analysis System Technique [2, 22, 23], that are listed on the vertical axis of the matrix. Possible solution principles for each function are then listed on the horizontal axis. To 
form complete system architectures, various solution principles are combined to create different architectures.

The quantified matrix [16] gives the engineer immediate access to approximated properties of the complete system. Every potential subsolution is described either with physical or statistical equations, or a combination of these. Useful measures of merits are thereby quantified for each solution alternative. By aggregating the properties for the chosen subsolutions a quantified value of the complete system can be obtained. To create the quantified matrix, mathematical models of the solution principles should be established first. These models express the principles as functions of the requirements and other parameters. The properties of a solution element are also often dependent on other solution elements within the chosen architecture, and one solution principle might require or exclude other solution principles for other functions.

If the quantified matrix is implemented in a computerized environment, multiobjective optimization algorithms could be used to search for a set of optimal architectures, known as Pareto-optimal solutions [25, 26]. In the next section, a mathematical framework is presented that facilitates the formulation of the multiobjective optimization problem.

\section{Multiobjective optimization-based embodiment design framework}

This section details the multiobjective optimization framework we developed to support the embodiment design process of mechatronic systems based on the morphological matrix and the design structure matrix used to formalize the compatibility and dependency relationships between the solution principles. These matrices should be used within a mathematical to formulate the multiobjective optimization framework.

The objectives of the multiobjective optimization-based embodiment design framework detailed in this section. For each technical function expressed in the functional architecture, solution principles or technical solutions are extracted from solution databases. These solution principles shape the morphological matrix (see Table 1). A compatibility analysis is then performed to identify incompatibility and dependency relationships between each pair of solution principles. This analysis is synthetized using the design structure matrix. The objective of the multiobjective optimization-based embodiment design framework is then to combine some solution principles in order to build mechatronic products that concretize all technical functions. Input data from our framework is then the morphological matrix summarizing the solution principles that can be considered to realize a given technical function, and the output data are possible architectures for the mechatronic system.

\subsection{The multiobjective optimization framework}

In the following, we detail how this formalization can be integrated within a global multiobjective optimization framework to generate and select solution architectures. 
During the functional architecting phase, ahead from the embodiment design, the product has been described by a set of technical functions that have to be translated into a solution architecture, and evaluation criteria and constraints have been defined from the customer requirements, the standards, the legislation, etc. This functional architecture as well as the evaluation criteria and constraints constitute the input data from our optimization framework. Figure 2 presents the optimization framework we developed in order to support the embodiment design process of mechatronic devices.

This framework has five steps:

- The first step analyzes the compatibility and dependency relationships between the solution principles from the morphological matrix. This analysis aims to identify combination rules for the solution principles. The design structure matrix is considered to formalize this analysis.

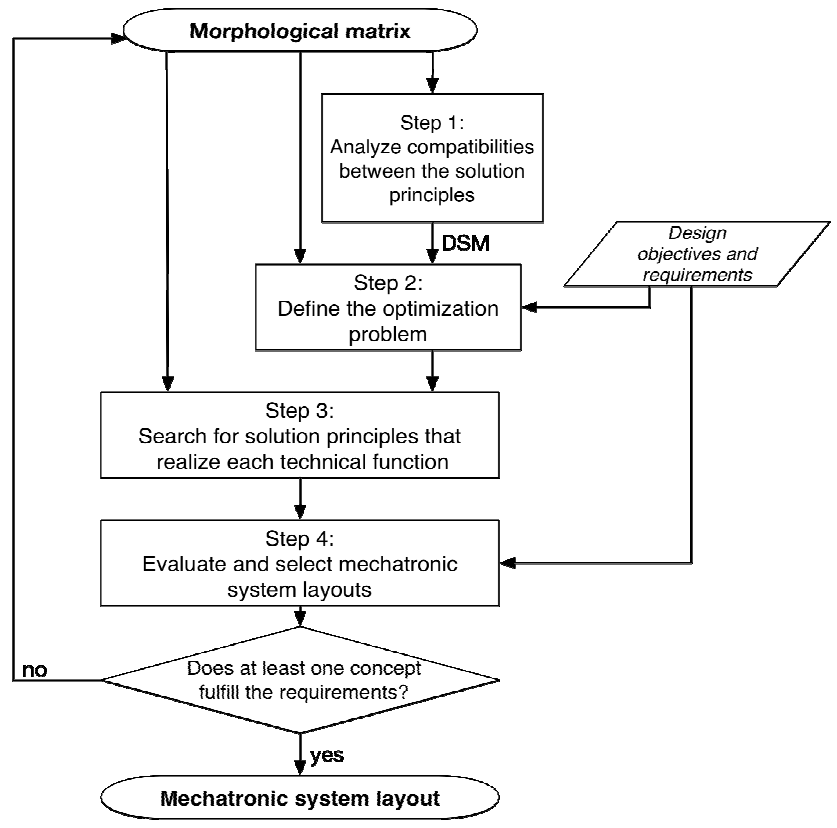

Fig.2. Our optimization-based embodiment design framework

- The second step aims to translate the morphological and design structure matrices, as well as the evaluation criteria and constraints from the design problem as a multiobjective optimization problem. This translation is performed using the mathematical formulation that will be presented in subsection 3.2.

- The third step is intended for solving the problem defined in the previous step using multiobjective optimization algorithms or heuristics. This problem solving process leads to the definition of solution architectures built by combining the solution principles, defined in the morphological matrix, according to the combination rules extracted from the compatibility analysis. The multiobjective- 
oriented approach has the effect of proposing not one but several optimal solutions, commonly represented as the Pareto frontier.

- The fourth and final step evaluates the solution architectures resulting from the optimization algorithms regarding the evaluation criteria and constraints and selects the best satisfactory architectures. This evaluation and selection process uses multicriteria decision analysis and decision-making tools, such as Electre, Prométhée [27]. If no architecture fits the requirements, more solution principles may be added in the morphological matrix and new architectures may be defined. If the process still fails to find a satisfactory solution, inventive solutions [24, 28, $29]$ should perhaps be required to solve the problem. This inventive architecture creation is not detailed in this paper.

In this subsection, we presented our multiobjective optimization framework intended for computerizing the product architecting process of mechatronic devices. This framework however requires translating the morphological and compatibility matrices under a mathematical optimization problem. In the next subsection, we detail how we realized this translation.

\subsection{Mathematical formulation of the optimization framework}

This subsection aims to propose a mathematical formulation of the optimization framework detailed in the previous subsection. This mathematical formulation is used to perform the step 2 in our framework, presented in figure 1, related to the definition of the optimization problem.

The evaluation of the different architectures uses criteria and constraints based on the customer requirements and expressed during the functional analysis phase: some evaluation criteria (named $C_{\alpha}$ ) described as an objective function to minimize or maximize, and inequality (named $\Gamma_{\beta}$ ) and equality constraints (named $\Phi_{\gamma}$ ). These elements depend on the characteristics of the architecture. We may then define each criteria and constraints as functions of the characteristics of the architecture, represented by the vector $(X, y)$ and external parameters $\psi$ such as the characteristics of the environment.

$$
\begin{array}{ccc}
\text { Minimize } & C_{\alpha}(X, y, \psi) & \forall \alpha \in\left\{1, \ldots, N_{C}\right\} \\
\text { subject to } & \Gamma_{\beta}(X, y, \psi) \leq 0 & \forall \beta \in\left\{1, \ldots, N_{\Gamma}\right\} \\
& \Phi_{\gamma}(X, y, \psi)=0 & \forall \gamma \in\left\{1, \ldots, N_{\Phi}\right\} \\
& \sum_{j=1}^{m} x_{i j}=1 & \forall i \in\{1, \ldots, n\} \\
& x_{a b}+x_{c d} \leq 1 & \left\{\forall a b, c d \in\{1, \ldots, m n\} \mid d_{a b, c d}=-1\right\} \\
& x_{a b}-x_{e f} \leq 0 & \left\{\forall a b, e f \in\{1, \ldots, m n\} \mid d_{a b, e f}=1\right\} \\
x_{i j}=0 & \left\{\forall i \in\{1, \ldots, n\}, j \in\{1, \ldots m\} \mid j \geq m_{i}+1\right\} \\
x_{i j} \in\{0,1\} &
\end{array}
$$

Where : $\mathrm{m}_{\mathrm{i}}$ correspond to the number of solution principles available for the function $i$, and $\mathrm{m}=\max \left(\mathrm{m}_{\mathrm{i}}\right), \forall \epsilon\{1, \ldots, \mathrm{n}\} . N_{C}, N_{\Gamma}, N_{\Phi}$ respectively correspond to the number of criteria, inequality constraints and equality constraints defined in the design problem. And : 


$$
d_{a b, c d}=\left\{\begin{array}{cc}
1 & \text { if } x_{a b} \text { requires } x_{c d} \\
-1 & \text { if } x_{a b} \text { is not compatible with } x_{c d} \\
0 & \text { otherwise }
\end{array}\right.
$$

The problem stated in the equation (1) can be solved using multiobjective optimization algorithms [30] such as NSGA-II [31], MOGA [32]. The next subsections present an implementation of the mathematical framework as an optimization framework and as a Java software tool.

\subsection{Implementation of the optimization framework}

The optimization framework presented in 3.1 and the mathematical framework introduced in 3.2 should be implemented in a generic computerized framework for embodiment design and optimization. Figure 3 illustrates the process that includes support for embodiment design optimization.

In this framework, the morphological matrix is obtained from the search for solution principles that can be used to realize each technical function. Then, the optimization algorithm modifies the optimization variables $\mathrm{y}$ and the matrix $\mathrm{X}$ in order to optimize the system represented by its model. Models output are processed to determine values of the objective and constraint functions, which will become the input to the next iteration of the optimization algorithm, as well as the design structure outputted by the compatibility analysis. The solution architectures that pass the evaluation process are filtered using the decision-support approach to select the best architecture(s).

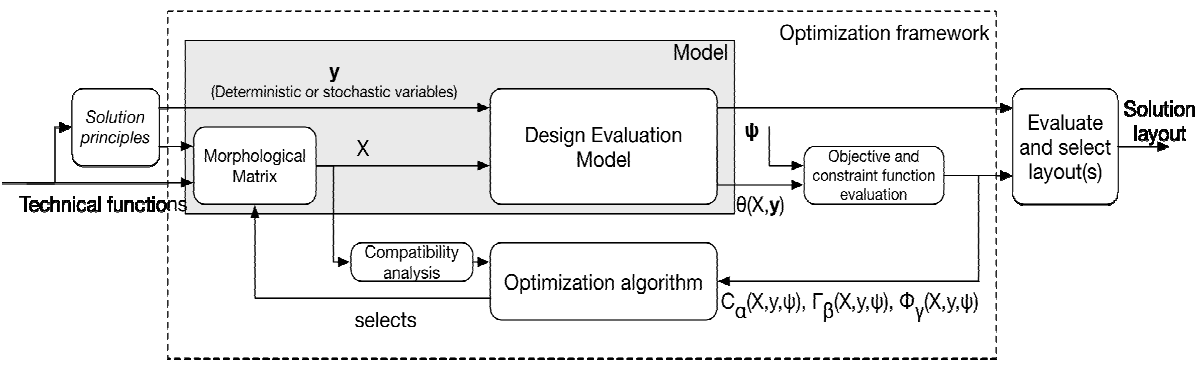

Fig.3. Implementation of the optimization framework

Based on the set of technical functions (input data of the framework), the "Solution Principles" aims finding the solution principles that can be considered to concretize each technical function. These solution principles are then presented within the morphological matrix ("Morphological Matrix" block). The mathematical formulation presented in 3.2 is implemented in the optimization framework within the "Objective and constraint function evaluation" block to evaluate the model outputs and define the values for the criteria and constraints constituting the optimization problem. The design evaluation model is determined from the different solution principles are modeled by a set of equations used to calculate the characteristics of the solution principle. As formulated in 3.2, the morphological matrix uses a binary representation 
whose processing then activates the set of equations related to the selected solution principles. These solution principles are used to determine the properties of the complete architecture.

In the next section, we present an application of the presented optimization framework to the embodiment design of a wind turbine.

\section{Embodiment design of a wind turbine}

In this section, we studied one embodiment design example aiming to define solution architectures for a wind turbine. Based on the morphological matrix presented in Table 1, we analyzed the compatibilities and dependencies between the solution principles from the matrix. We mainly considered different rules. For example, to connect a principle $\mathrm{A}$ with a principle $\mathrm{B}$, at least one output port of principle A and one input port of principle B should have the same type. That means that the generator outputs an electrical current and can, for example, only be connected to electrical components (rectifier).

\subsection{Compatibility analysis - Design evaluation model}

A design evaluation model of the wind turbine has been developed to get a quantitative evaluation of the architectures generated by the optimization algorithm regarding the criteria and constraints from the design problem. In order to reduce the calculation time required for the optimization, we considered simplified static models that do not require time simulation.

We modeled the aerodynamic model based on the Betz equation [33]. The aerodynamic power caught by the blades can be expressed by :

$$
P_{b}=1 / 2 \rho S C_{p} V^{3}
$$

Where $P_{b}$ is the power generated by the blades, $\rho$ the density of air, $S$ the surface covered by the blades, $C p$ the power coefficient and $V$ the wind speed.

The power coefficient depends of the number of blades, their shapes, their orientation, and their materials. However this coefficient is usually determined experimentally using wind tunnels, some empirical relations can be found in the literature. Among these expressions, we retained this relation that expresses the power coefficient as a function depending of the number of blades, the material used [34].

Then we modeled Electrical power and energy. Considering the power produced by the rotor (16), we may express the electrical power $P e$ supplied to the cottage as a function of $P_{b}$ and the power efficiencies $\eta_{i}$ of the $N$ components located between the rotor and the power grid (such as the transmission, generator, storing modules).

$$
P_{e}=\left(\prod_{(\mathrm{i}=1)^{\mathrm{N}}} \eta_{\mathrm{i}}\right) P_{b}
$$

With the wind speed $V$ ranges between $0 \mathrm{~m} / \mathrm{s}$ and $V_{\max }, P(v=V)$ the probability of having wind speed equal to $\mathrm{V}$. This wind distribution follows a Weibull distribution. Then we express the electrical energy as:

$$
E_{\varepsilon}=\Xi \sum_{i=0}^{M-1} C_{p}\left(V_{i}\right) \mathbb{P}\left(V_{i}\right) V_{i}^{3}
$$


With

$$
\Xi=\frac{1}{2} \Psi \rho S=\frac{1}{2} \frac{365 \times 24}{1000}\left(\prod_{j=1}^{N} \eta_{j}\right) \rho S=4.38\left(\prod_{j=1}^{N} \eta_{j}\right) \rho S
$$

The second criteria defined in the design problem aims to reduce the cost of energy. To determine the global cost $C$, can be expressed as:

$$
C=\sum_{(i=1)}^{N} C_{i}
$$

With $C_{i}$ : cost of the i-th component, and $N$ : number of components in the system.

The reliability of the wind turbine can be expressed using the Mean Time To Failure $(M T T F)$. In this study, we considered that the reliability law $R_{i}(t)$ for each component $\mathrm{i}$ follows an exponential law, the reliability law of the overall wind turbine $R(t)$ can be expressed as:

$$
R(t)=\prod_{i=1}^{N} R_{i}(t)=\prod_{i=1}^{N} \exp \left(-\chi_{i} t\right)=\exp \left[-\left(\sum_{i=1}^{N} X_{i}\right) t\right]
$$

\subsection{Application of the optimization framework on the case study}

We obtained the following optimization problem according to the design problem expressed in subsection 1.1

$$
\begin{array}{ll}
\text { maximize } & 4.38\left(\prod_{j=1}^{N} \eta_{j}\right) \rho S \sum_{i=0}^{M-1} C_{p}\left(V_{i}\right) \mathbb{P}\left(V_{i}\right) V_{i}^{3} \\
\text { minimize } & \sum_{i=1}^{N} C_{i} \\
\text { maximize } & {\left[\sum_{i=1}^{N} \chi_{i}\right]^{-1}} \\
\text { subject to } & \left(\prod_{j=1}^{N} \eta_{j}\right) P_{b} \geq 20,000 \mathrm{~W}
\end{array}
$$

The optimization process therefore aims to identify, for each technical function exposed in Table 1 , the best technical solution to obtain the best combinations of optimal solutions for the wind turbine.

We implemented the equations (3) to (9) in Matlab in order to computerize the evaluation and the optimization process. Matlab is then integrated into ModeFrontier software that has been used to solve that problem. We considered the following parameters for the optimization problem solving: 1) Algorithm: NSGA II [31]; 2) Number of generations: 100; 3) Population size: 100; 4) Crossover probability: 0.2; Mutation probability: 0.8 .

Using optimization, we obtained the results shown in Figure 4. This figure presents the evaluation of different architectures and parameters (vectors $\mathrm{y}$ and $\psi$ in equation (1) for the three criteria exposed in (9). This figure shows evaluation from the solution architectures generated by the optimization algorithm regarding cost, energy and 
reliability. The first criterion should be minimized and the last two criteria should be maximized.

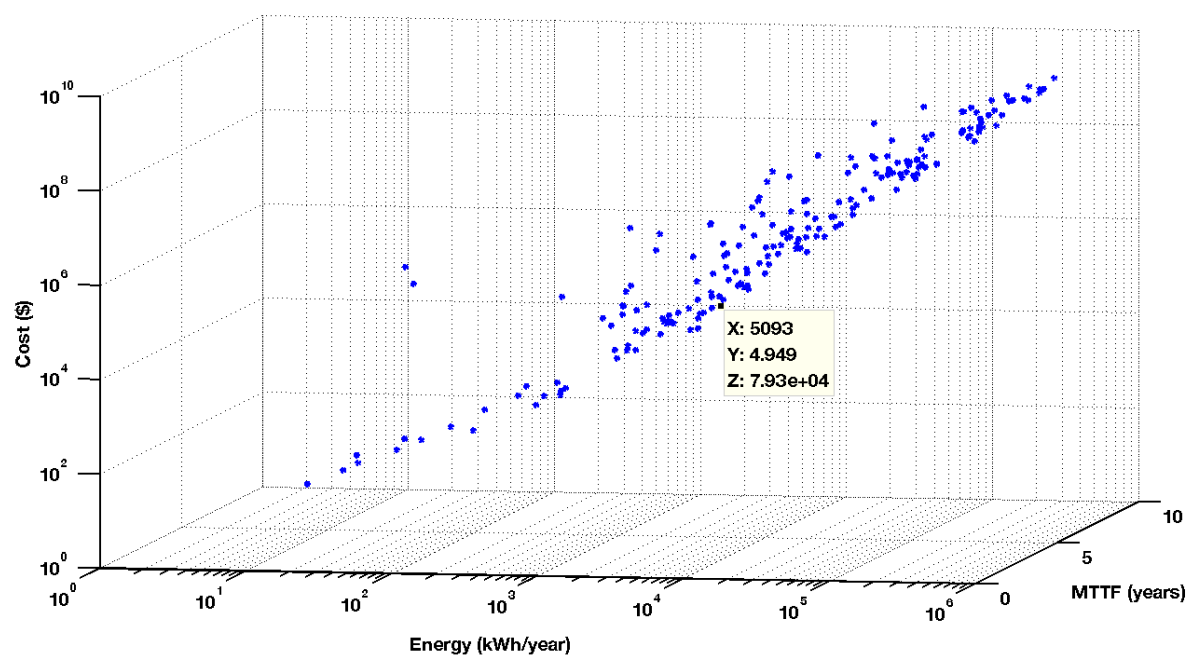

Fig.4. Optimization results

In this figure, each scatter point represents the evaluation of the optimization criteria for several architectures and sets of parameter. Based on this figure, we selected the marked solution which will be considered as the optimal solution. We analyzed solutions from the Pareto front (step 4 from our approach) in order to extract an architecture that will be improved during the detailed design phase. This step is not furthermore detailed in this paper and will be the subject of future communications.

\section{Conclusion}

This paper dealt with the embodiment design of mechatronic devices. In this paper we proposed a multiobjective optimization framework intended to computerize the process for combining and selecting solution architectures built by aggregating solution principles from the morphological matrix. In a first part, we described the morphological matrix as a multiobjective optimization problem and use the design structure matrix to analyze the compatibilities between the solution principles. Then, in a second part, we presented the optimization framework showing how the proposed mathematical formulation can be integrated within the embodiment design process. And, in a third part, we exposed how this optimization can be implemented. Finally, in a final part, we successfully showed how the proposed framework could be used to solve a case study aiming to design a wind turbine and using Matlab and ModeFrontier.

This framework however shows weaknesses regarding the time required to program the optimization problem using Matlab, the efficiency of the implementation 
of the optimization framework within Matlab. These weaknesses will be solved using the dedicated software application that is currently in development. It will be the object of further communications. Finally, characterizing the optimization framework using more complex systems can also be seen as an outlook.

\section{References}

1 Pahl G., Beitz W., Feldhusen J., Grote K.-H., Engineering Design : A systematic approach, 3rd edition ed., Springer, (2007).

2 Tan S., Enhanced Functional Analysis System Technique for Managing Complex Engineering Projects, University of Missouri--Rolla, (2007).

3 Yoshida K., Functional Analysis, Springer, (1980).

4 Cavallucci D., T. Eltzer, Structuring knowledge in inventive design of complex problems, Procedia Eng., Bergamo, 694-701, (2011),.

5 Ahmad A., Andersson K., Sellgren U., A model-based and simulation-driven methodology for design of haptic devices, Mechatronics, 24, 805-818, (2014).

6 Yan W., Zanni-Merk C., Cavallucci D., Collet P., An ontology-based approach for inventive problem solving, Engineering Applications of Artificial Intelligence, 27, 175190, (2014).

7 Cardillo A., Cascini G., Frillici F., Rotini F., Computer-aided embodiment design through the hybridization of mono objective optimizations for efficient innovation process, Comput Ind, 62, 384-397, (2011).

8 Scaravetti D., Pailhes J., Nadeau J.-P., Sebastian P., Aided Decision-Making for an Embodiment Design Problem, in: A. Bramley, D. Brissaud, D. Coutellier, C. McMahon (Eds.) Advances in Integrated Design and Manufacturing in Mechanical Engineering, Springer Netherlands, 159-172, (2005).

9 Kuhm D., Knittel D., New design of robust industrial accumulators for elastic webs, Milano, pp. 8645-8650, (2011).

10 Scheidl R., Winkler B., Model relations between conceptual and detail design, Mechatronics, 20, 842-849, (2010).

11 Casner D., Houssin R., Renaud J., Knittel D., Contribution to the embodiment design of mechatronic system by evolutionary optimization approaches, Joint Conference on Mechanical, Design Engineering \& Advanced Manufacturing, Toulouse, France, (2014).

12 Casner D., Houssin R., Renaud J., Knittel D., Optimization as an innovative design approach to improve the performances and the functionalities of mechatronic devices, Triz Future Conference 2014 - Global Innovation Convention, Elsevier, Lausanne, Switzerland, (2014).

13 Cross N., Engineering Design Methods: Strategies for Product Design, Wiley, 2008.

14 Ficalora J.P., Cohen L., Quality Function Deployment and Six Sigma, Second Edition: A QFD Handbook, Pearson Education, (2009).

15 Bossert J.L., Quality Function Deployment: The Practitioner's Approach, Taylor \& Francis, (1990).

16 Ölvander J., Lundén B., Gavel H., A computerized optimization framework for the morphological matrix applied to aircraft conceptual design, Computer-Aided Design, 41, 187-196(2009).

17 Suh N.P., Axiomatic Design: Advances and Applications, Oxford University Press, Incorporated, (2001)

18 Suh N.P., Complexity: Theory And Applications, Oxford University Press on Demand, (2005). 
19 Browning T.R., Applying the design structure matrix to system decomposition and integration problems: a review and new directions, Engineering Management, IEEE Transactions on, 48, 292-306, (2001).

20 Zwicky F., Discovery, Invention, Research: Through the Morphological Approach, Macmillan, (1969)

21 Zwicky F., C.I.o. Technology, The morphological method of analysis and construction, California inst. of technol., (1948).

22 Singh A., Creative Systems in Structural and Construction Engineering, Taylor \& Francis, (2001).

23 Bytheway C.W., Function Analysis Systems Technique Creativity and Innovation, J. Ross Pub., (2007).

24 Altshuller G., L. Shulyak, S. Rodman, 40 Principles: Triz Keys to Innovation, Technical Innovation Center, (2002).

25 Deb K., Multi-objective optimization using evolutionary algorithms, John Wiley \& Sons, Chichester, (2001).

26 Frechard J., Knittel D., Drive requirements for elastic web roll-to-roll systems, Mechanism and Machine Theory, 66, 14-31 (2003).

27 Collette Y., Siarry P., Multiobjective optimization principles and case studies, Corr. 2nd print. ed., Springer, Berlin, (2004).

28 Cavallucci D., Integrating Altshuller's development laws for technical systems into the design process, CIRP Annals - Manufacturing Technology, 50, 115-120, (2001).

29 Chinkatham T., D. Cavallucci, Early feasibility evaluation of Solution Concepts in an Inventive Design Method Framework: Approach and support tool, Comput Ind, 67 1-16, (2015).

30 Zitzler E., Laumanns M., Bleuler S., A tutorial on evolutionary multiobjective optimisation, (2004)

31 Deb K., Pratap A., Agarwal S., Meyarivan T., A fast and elitist multiobjective genetic algorithm: NSGA-II, Ieee T Evolut Comput, 6, 182-197, (2002).

32 Tan K.C., Khor E.F., Lee T.H., Multiobjective Evolutionary Algorithms and Applications, Springer London, (2006).

33 Betz A., Introduction to the theory of flow machines, Pergamon Press, (1966).

34 Manwell J.F., McGowan J.G., Rogers A.L., Wind Energy Explained: Theory, Design and Application, Wiley, (2010).

35 Høyland A., Rausand M., System Reliability Theory: Models and Statistical Methods, Wiley, (2009).

36 Houssin R., Coulibaly A., An approach to solve contradiction problems for the safety integration in innovative design process, Comput Ind, 62, 398-406, (2011). 